\title{
Efficacy of ethyl formate as a disinfestation treatment for codling moth (Cydia pomonella) in apples
}

\author{
L.E. Jamieson, N.E.M. Page-Weir, M.J. Griffin, S.P. Redpath, \\ A. Chhagan and P.G. Connolly \\ The New Zealand Institute for Plant \& Food Research Limited, \\ PO Box $92169 \mathrm{Mt}$ Albert, Auckland \\ Corresponding author: Lisa.Jamieson@plantandfood.co.nz
}

\begin{abstract}
Codling moth (CM, Cydia pomonella) is a pest of quarantine concern on apple exports to Asian markets. Apples exported to Japan must be fumigated with methyl bromide $(\mathrm{MB})$ and then cold stored. Ethyl formate (EF), as an alternative to $\mathrm{MB}$, is effective against a range of pests. This project investigated the effectiveness of EF to control an internal pest such as CM by determining the responses of key insect stages without fruit and inside apples. Trials without fruit in a $2 \mathrm{~h}$ fumigation showed that late-stage CM eggs and third instar CM larvae were the most tolerant life stages, requiring a mean concentration of $1.34-1.94 \% \mathrm{EF}$ to achieve $99 \%$ mortality, but $100 \%$ mortality of $4^{\text {th }} / 5^{\text {th }}$ instar CM larvae. Trials with CM in fruit in a $2 \mathrm{~h}$ fumigation showed that $1.13 \%$ EF resulted in $53.4 \%$ mortality of $4^{\text {th }} / 5^{\text {th }} \mathrm{CM}$ larvae inside apples. Increasing the mean concentration to $2.4 \% \mathrm{EF}$ increased the mortality of $4^{\text {th }} / 5^{\text {th }}$ larvae inside apples to $85.2 \%$.
\end{abstract}

Keywords fumigation, postharvest, most tolerant stage, mortality responses, methyl bromide alternative.

\section{INTRODUCTION}

Codling moth (CM, Cydia pomonella L. (Lepidoptera: Tortricidae)), is a pest of quarantine concern on apple exports to Taiwan, China, Japan, South Korea. Access for New Zealand apples to Japan requires methyl bromide (MB) fumigation followed by cold storage for 25 d (Anon 1993; Dentener et al. 1998; Waddell 1993) to provide the very high level of quarantine security required by this market for specific varieties of apples. Apples exported to Taiwan and China do not require fumigation but instead producers must comply with specific orchard and packhouse management practices as well as a CM orchard monitoring programme (MPI 2013). These practices and programmes are estimated to have reduced codling moth incidence to $<5 \times 10^{-7}$ (J.T.S. Walker, Plant \& Food Research, personal communication), which exceeds the phytosanitary standard that was achieved with fumigation and cold storage. The cost of fumigating or complying with these management and monitoring programmes adds significantly to the cost of exporting apples. Moreover, some treatments such as MB fumigation can reduce apple quality (Drake \& Moffitt 1998; Schimanski et al. 2005; Soma et al. 1997), and result in organically-grown apples losing their lucrative organic status. Although MB used for quarantine is exempt reduction and phase out 
under the Montreal Protocol (UNEP 2012), many countries have banned all uses including those for quarantine. New Zealand will require all MB fumigation facilities to capture any emissions after 2020 (EPA 2011). Therefore, alternatives to MB are being sought by the apple industry to ensure continued market access should MB be restricted, become uneconomical or become unavailable.

Ethyl formate $(\mathrm{EF})$ is a generally recognised as safe (GRAS) fumigant that is reported to control many pest species (Chhagan et al. 2013; De Lima 2009, 2010; Griffin et al. 2013; Jamieson et al. 2013, 2014, 2015; Pupin et al. 2013; Simpson et al. 2004, 2007; van Epenhuijsen et al. 2007). It has the potential to be used in a management programme with no detectable residues. EF combined with $\mathrm{CO}_{2}$ is commercially available in New Zealand as VAPORMATE ${ }^{\mathrm{Tn}}$. Lepidopterans such as CM tend to be more tolerant of EF than thrips, scale insects and mealybugs (De Lima 2009, 2010), with eggs often identified as the most tolerant life stage (Ducom 2006; Jamieson et al. 2015). Insects inside fruit, i.e. fruit fly eggs and larvae, can often be more tolerant to EF than external insects (C.R. De Lima, AgHort Solutions, personal communication).

This study determined the effect of insect location on EF treatment efficacy by comparing the most tolerant life stage of CM to $\mathrm{EF}\left(+\mathrm{CO}_{2}\right)$ without apples and inside apples.

\section{MATERIALS AND METHODS Preparation and assessment of life stages off fruit}

CM early-stage eggs (1-2 days old), late-stage eggs (4-5 days old), $1^{\text {st }}, 3^{\text {rd }}$ and $5^{\text {th }}$ instar larvae were provided from a laboratory colony reared on an artificial diet at Plant \& Food Research (PFR), as described by Jamieson et al. (2013). Wax paper with > 100 early or late CM eggs were placed for EF treatment in separate plastic vials $(11 \mathrm{~cm}$ high by $4 \mathrm{~cm}$ diam.) with stainless steel gauze at each end. First instar larvae (100 per vial) were placed on artificial diet inside similar vials. Late $3^{\text {rd }}$ instar CM larvae and non-diapausing $5^{\text {th }}$ instar CM larvae (70 per container) were placed separately inside larger plastic containers $(10 \mathrm{~cm}$ high x $10.5 \mathrm{~cm}$ diameter at top tapering to $8.5 \mathrm{~cm}$ diameter at the base) with stainless steel gauze at each end, containing diet and tissue paper. After exposure to $\mathrm{EF}$, the containers containing life stages were stored at $20^{\circ} \mathrm{C}, 16: 8 \mathrm{~h}$ light:dark until assessment. Eggs were assessed $9 \mathrm{~d}$ after treatment and recorded as hatched or unhatched. CM larvae were touched gently with forceps and assessed as live (movement) or dead (no movement).

\section{Preliminary trial to determine EF concentration range}

$\mathrm{CM}$ in containers were treated with one of seven EF concentrations ranging from a target of 0 to $2.5 \% \mathrm{EF}\left(+\mathrm{CO}_{2}\right.$, at the $\mathrm{CO}_{2}$ rate in accordance with the ratio of EF: $\mathrm{CO}_{2}$ in VAPORMATE ${ }^{\mathrm{Tx}}$ ) for either $1,2,3$ or $4 \mathrm{~h}$ at $15^{\circ} \mathrm{C}$. Treatments were conducted in the Volatile Treatment Facility (VTF) consisting of 28 stainless steel chambers (76.8 L each) at PFR in Auckland, as described by Jamieson et al. (2014). In a preliminary trial, single replicates were tested for 1, 2, 3 and $4 \mathrm{~h}$ to determine an appropriate treatment duration. Based on the results of this trial, a $2 \mathrm{~h}$ duration was selected for the life stage tolerance testing. Three to four replicates were undertaken of each life stage.

\section{Fumigant measurements and exposure conditions}

The concentration of EF introduced to each chamber was controlled automatically by a computer that also sampled EF concentration at the beginning, during and at the end of each treatment. The EF concentration in each sample of $50 \mu \mathrm{L}$ in a sampling loop was measured using a gas chromatograph (Shimazdu GC-2014 fitted with Restek ${ }^{\circledR}$ capillary column $30 \mathrm{~m}$ x $0.25 \mathrm{~mm}$ x $0.25 \mu \mathrm{L}) . \mathrm{CO}_{2}$ was measured by manually taking a $1 \mathrm{~mL}$ sample from each chamber and injecting it into a gas analyser. 


\section{EF fumigation of life stages inside fruit}

Although the $3^{\text {rd }}$ instar CM larva was the most tolerant larval stage as a result of the preliminary trial described above, late $4^{\text {th }}$ instar/ early $5^{\text {th }}$ instar non-diapausing CM larvae were selected for use inside fruit because their survival rates are higher than the earlier life stages when artificially placed inside apples.

'Scired'/Pacific Queen ${ }^{\mathrm{Tm}}$ apples were infested with codling moth larvae, as described by Dentener et al. (1998) and Rogers et al. (2013). Three evenly-spaced holes were punched in each apple using a compressed-air driven punch. Actively-feeding, late $4^{\text {th }} /$ early $5^{\text {th }}$ instar larvae were obtained from the same codling moth colony as described above. They were removed from their tubes containing diet and placed inside one of three holes in an apple. Each larva was retained in its hole by placing a plug of agar gel ( $2 \%$ agar in water) across the entrance and then covering it with a piece of masking tape. Groups of 17 infested apples (each with three larvae, total 51) were placed in an insect-proof, nylon-mesh bag. Additionally, 50 actively-feeding late $4^{\text {th }}$ instars/early $5^{\text {th }}$ instar CM larvae were removed from their tubes and placed in containers as described above in the preliminary trial.

The following day, the apples were checked to see that the larvae had not escaped. Each bag of 17 codling moth infested apples, along with 83 non-infested apples and the containers of larvae, were placed in $76.8 \mathrm{~L}$ chambers in the VTF. Codling moth larvae and apples were exbposed to the target EF concentrations between 0 and 3.0\% $\mathrm{EF}$ (with $\mathrm{CO}_{2}$ to mimic VAPORMATE ${ }^{\mathrm{m}}$ ) for $2 \mathrm{~h}$ at $15^{\circ} \mathrm{C}$. Mean $\mathrm{EF}$ and $\mathrm{CO}_{2}$ concentrations were recorded during the treatment. After exposure to $\mathrm{EF}, \mathrm{CM}$ larvae in containers and inside apples were stored at $20^{\circ} \mathrm{C}$ for 3 days until the larval mortality was assessed using the methods described above.

\section{Statistical analyses}

To assess the mortality response, non-parametric LOESS fits (Cleveland et al. 1992) were calculated and plotted on an arcsine transformed scale (e.g. transform percentage $\mathrm{p}$ by $\arcsin [\operatorname{sqrt}(\mathrm{p} / 100)])$ in R ( R Core Team 2015) (Figures 1-3). For each insect life stage, smooth lines were drawn through the percentage mortality points after exposure to $\mathrm{EF}+\mathrm{CO}_{2}$, at each actual measured $\mathrm{EF}$ treatment concentration. The error bars represent the root-mean-square of the errors of the fit of each line and represent approximately uniform variability over the entire mortality range on the arcsine scale.

Concentration mortality data for each replicate were fitted using the generalised linear model (Dobson \& Barnett 2008) capability of R with the complementary log-log (clog-log) link (Preisler \& Robertson 1989) and the actual EF concentration as the explanatory variable. Specifically, the assumed form of response was $\log (-\log (1-p))=a+b C$, where $\mathrm{p}=$ expected mortality, and $\mathrm{C}=$ concentration of EF. The coefficients from the models were used to derive the estimated lethal EF concentration to achieve $99 \%$ mortality $\left(\mathrm{LC}_{99}\right)$, the concentration to achieve a mortality of $\mathrm{cm}+(1-\mathrm{cm}) \times 0.99$, where $\mathrm{cm}$ was the control mortality. Two possible sources of extraneous mortality were considered: handling and treatment with $\mathrm{CO}_{2}$. The mortality attributed to those sources was compared using a simpler binomial GLM and found not to be significantly different. Consequently, the handling control and treatment control mortality data were combined and used as the control mortality $(\mathrm{cm})$. For each life stage, a geometric mean LC and its associated standard error (SEM) were estimated, from which a $95 \%$ confidence interval (CI) was calculated. Non-overlap of the $95 \%$ CIs is approximately equal to a test for difference at $\mathrm{P}=0.01$.

\section{RESULTS \\ Preliminary trial to determine EF concentration range}

The target $\mathrm{EF}$ and $\mathrm{CO}_{2}$ concentrations, and the actual mean concentrations recorded, for the $2 \mathrm{~h}$ exposures of CM life stages without fruit are shown in Table 1.

As the EF exposure time increased, the mortality response of the CM life stages also increased (Figures 1A-E), and the lethal concentration estimates reduced (Table 3 ). First instars were the most susceptible with complete mortality of all EF-treated $1^{\text {st }}$ instars for all concentrations (Figure 
Table 1 Target percentage ethyl formate (EF) concentration and mean measured percentage EF and $\mathrm{CO}_{2}$ concentrations measured during Trial 1 to determine the life stage tolerance of codling moth to a 2-h ethyl formate treatment at $15^{\circ} \mathrm{C}$.

\begin{tabular}{ccc}
\hline Target EF $(\%)$ & Mean measured EF $(\%)$ & Mean measured $\mathrm{CO}_{2}(\%)$ \\
\hline Untreated control & 0 & 0 \\
$0\left(\mathrm{CO}_{2}\right.$ control $)$ & 0 & 13.56 \\
0.3 & 0.24 & 2.17 \\
0.6 & 0.48 & 4.24 \\
0.9 & 0.76 & 6.53 \\
1 & 1.42 & 8.23 \\
1.2 & 1.01 & 8.29 \\
1.3 & 1.55 & 8.69 \\
1.5 & 1.31 & 9.48 \\
1.7 & 1.41 & 5.42 \\
2 & 1.74 & 12.44 \\
2.5 & 2.01 & 15.31 \\
\hline
\end{tabular}

1C), therefore lethal concentration estimates were not able to be calculated (Table 3). For the other life stages (Figure 1A, B, D, E), a 1 h exposure was insufficient time for EF at the concentrations tested to cause high mortality of eggs or $3^{\text {rd }} / 5^{\text {th }}$ instar larvae (61-87\% mortality). Therefore, the lethal concentration estimates for $99 \%$ mortality were solely from extrapolations and may not provide a reliable indicator of the EF concentration likely to cause high mortality (Table 3 ). Third instar larvae and late-stage eggs were the most tolerant life stages for the 2-h EF exposures (Table 3, Figure 2). A $2 \mathrm{~h}$ exposure of $1.7 \%$ EF concentration has the potential to control $>99 \%$ of all CM life stages off fruit.

\section{EF fumigation of life stages inside fruit}

The target $\mathrm{EF}$ and $\mathrm{CO}_{2}$ concentrations, and the actual mean concentrations recorded, for the $2 \mathrm{~h}$ exposures of CM life stages inside fruit and in containers are shown in Table 2.

Although the concentration of EF was close to the target at the beginning of treatments, it lowered to between 54 and $69 \%$ of the target after 2-h (Table 2). EF is reported to disassociate in contact with fruit, which could account for the reduced concentrations observed in these experiments. The mortality responses of $\mathrm{CM}$ larvae outside and inside apples to the mean measured EF concentration is shown in Figure 2. All $4^{\text {th }} / 5^{\text {th }}$ instar CM larvae died when exposed to a mean EF concentration of $1.12 \%$ (target of $1.5 \%$ $\mathrm{EF}$ ) or greater (Figure 3 ). However, only $67 \%$ of CM larvae inside apples died when exposed to $1.12 \%$ EF concentration (Figure 3). Increasing the measured EF concentration to $2.43 \%$ (target $3.0 \%)$ resulted in $85.2 \%$ mortality of CM larvae inside apples after a $2 \mathrm{~h}$ exposure to EF (Figure 3 ).

\section{DISCUSSION}

This study predicts that $>1.7 \%$ EF concentration for $2 \mathrm{~h}$ will result in $>99 \%$ mortality of CM eggs, $1^{\text {st }}, 3^{\text {rd }}$ and non-diapausing $5^{\text {th }}$ instar larvae outside fruit. This lethal concentration for $99 \%$ mortality of CM is similar to estimates for other lepidoptera such as the lightbrown apple moth (Epiphyas postvittana) (De Lima 2009), the brownheaded leafroller (Ctenopseustis obliquana) and the greenheaded leafroller (Planotortrix excessana) (L.E. Jamieson, Plant \& Food Research, unpublished data). However, Simpson et al. (2007) reported that omnivorous leafroller pupae were more tolerant to EF. It may be prudent to determine the tolerance of pupal life stages to EF fumigation in the future, although pupae of the species mentioned are not likely to be found on fruit. 
Table 2 Target and mean measured ethyl formate (EF) concentrations at the start and the end of the treatments for each concentration and the mean measured $\mathrm{CO}_{2}(\%)$. The trial compared the tolerance of codling moth life stages in containers with the same life stages contained in fruit.

\begin{tabular}{ccccc}
\hline $\begin{array}{c}\text { Target EF conc. } \\
(\%)\end{array}$ & $\begin{array}{c}\text { Initial measured } \\
\text { EF conc. }\end{array}$ & $\begin{array}{c}\text { Final measured } \\
\text { EF conc. }\end{array}$ & $\begin{array}{c}\text { Mean measured } \\
\text { EF conc. }\end{array}$ & $\begin{array}{c}\text { Measured } \mathrm{CO}_{2} \\
\text { conc. }\end{array}$ \\
\hline Handling control & 0.00 & 0.00 & 0 & 0.00 \\
$\mathrm{CO}_{2}$ control & 0.00 & 0.00 & 0 & 28.46 \\
0.9 & 0.96 & 0.52 & 0.74 & 9.475 \\
1.2 & 1.22 & 0.75 & 0.98 & 12.41 \\
1.5 & 1.33 & 0.92 & 1.12 & 15.36 \\
2.0 & 2.00 & 1.25 & 1.63 & 19.85 \\
2.5 & 2.60 & 1.76 & 2.18 & 23.72 \\
3.0 & 3.05 & 1.80 & 2.43 & 27.11 \\
\hline
\end{tabular}

Table 3 Mean lethal ethyl formate (EF) concentration (\%) predicted for $99 \%$ mortality $\left(\mathrm{LC}_{99}\right)$ of various life stages of codling moth, along with $95 \%$ confidence intervals (CIs), maximum mean percentage mortality and mean measured EF concentration and the number of individuals treated for each life stage and EF treatment duration at $15^{\circ} \mathrm{C}$.

\begin{tabular}{|c|c|c|c|c|c|}
\hline Life stage & $\begin{array}{c}\text { Treatment } \\
\text { duration }(\mathrm{h})\end{array}$ & Mean $\mathrm{LC}_{99}$ & $95 \% \mathrm{CI}$ & $\begin{array}{c}\text { Mean } \\
\text { maximum } \\
\text { mortality }^{1}\end{array}$ & $\mathrm{~N}$ treated \\
\hline \multirow[t]{4}{*}{ Early egg } & 1 & 2.27 & $1.72-3.00$ & $86.86(1.39)$ & 731 \\
\hline & 2 & 1.35 & $1.17-1.55$ & $100(1.56)$ & 4293 \\
\hline & 3 & 1.2 & $0.91-1.59$ & $100(1.32)$ & 746 \\
\hline & 4 & $\mathrm{NA}^{2}$ & NA & $100(0.88)$ & 876 \\
\hline \multirow[t]{4}{*}{ Late egg } & 1 & 3.45 & $2.62-4.56$ & $61.54(1.39)$ & 781 \\
\hline & 2 & 1.86 & $1.64-2.11$ & $100(2.01)$ & 4239 \\
\hline & 3 & 1.17 & $0.89-1.55$ & $100(1.22)$ & 818 \\
\hline & 4 & NA & NA & $100(0.88)$ & 920 \\
\hline \multirow[t]{4}{*}{$1^{\text {st }}$ instar } & 1 & $\mathrm{NA}$ & NA & $100(0.76)$ & 775 \\
\hline & 2 & NA & NA & $100(0.24)$ & 3918 \\
\hline & 3 & NA & NA & $100(0.76)$ & 764 \\
\hline & 4 & NA & NA & $100(0.88)$ & 769 \\
\hline \multirow[t]{4}{*}{$3^{\text {rd }}$ instar } & 1 & 2.02 & $1.53-2.67$ & $86.44(1.58)$ & 500 \\
\hline & 2 & 1.91 & $1.69-2.16$ & $98.63(2.11)$ & 2634 \\
\hline & 3 & 1.26 & $0.95-1.66$ & $100(1.62)$ & 527 \\
\hline & 4 & 1.43 & $1.08-1.89$ & $100(1.63)$ & 507 \\
\hline \multirow[t]{4}{*}{$5^{\text {th }}$ instar } & 1 & 1.93 & $1.46-2.54$ & 70.77 (1.39) & 594 \\
\hline & 2 & 1.46 & $1.27-1.67$ & $100(1.56)$ & 2792 \\
\hline & 3 & NA & NA & $100(1.06)$ & 566 \\
\hline & 4 & NA & NA & $100(1.11)$ & 564 \\
\hline
\end{tabular}

${ }^{1}$ EF concentration for first consistent $100 \%$ mortality point

${ }^{2} \mathrm{NA}=$ Insufficient mortality points below $100 \%$ measured to enable mean $\mathrm{LC}_{99}$ and CIs to be predicted. 

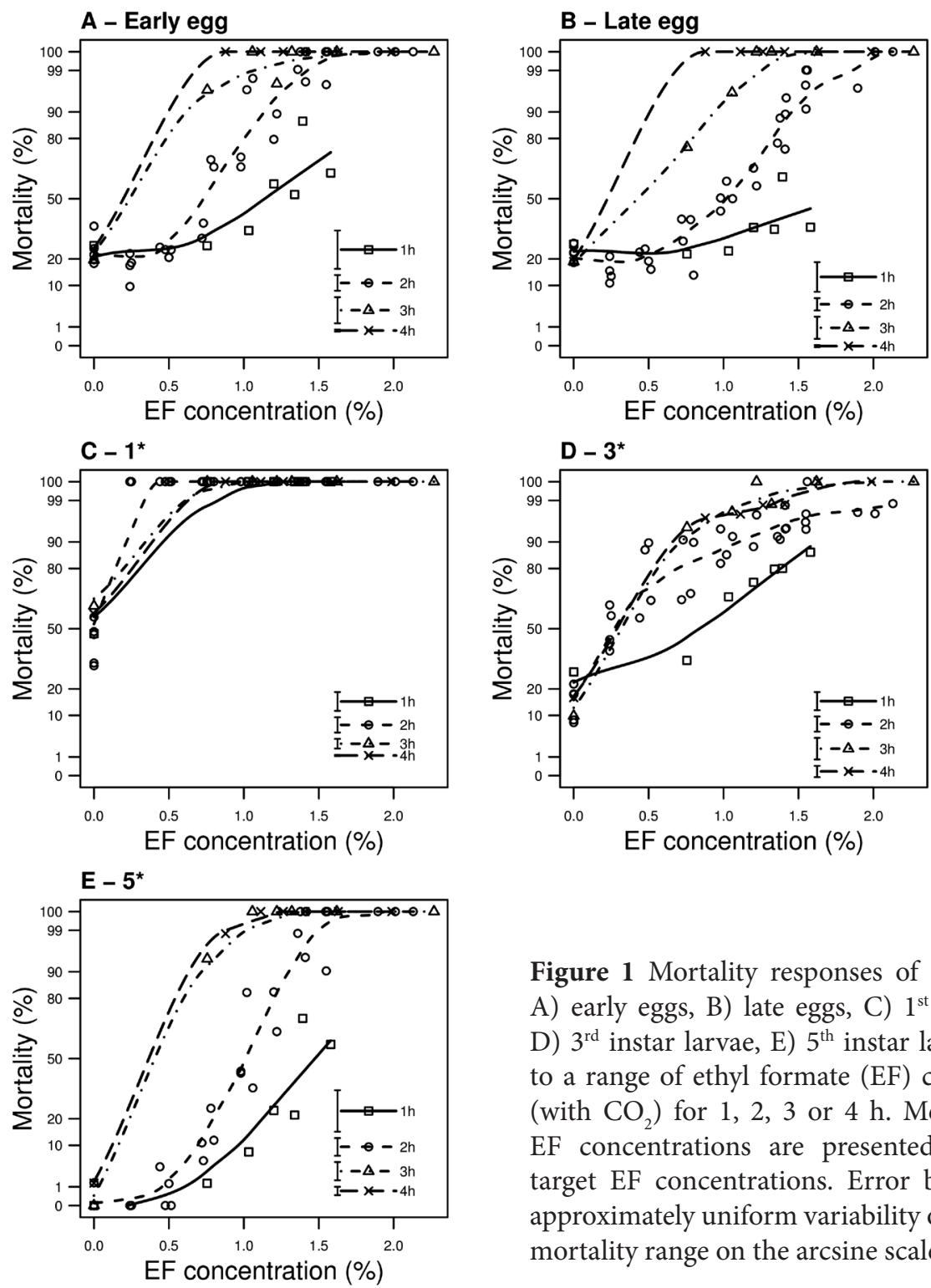

Figure 1 Mortality responses of codling moth A) early eggs, B) late eggs, C) $1^{\text {st }}$ instar larvae, D) $3^{\text {rd }}$ instar larvae, E) $5^{\text {th }}$ instar larvae exposed to a range of ethyl formate (EF) concentrations (with $\mathrm{CO}_{2}$ ) for $1,2,3$ or $4 \mathrm{~h}$. Mean measured $\mathrm{EF}$ concentrations are presented rather than target EF concentrations. Error bars represent approximately uniform variability over the entire mortality range on the arcsine scale.

CM larvae are an internal pest whose larvae can be found inside apples and pears. Research in Australia (C.F. DeLima, AgHort Solutions, personal communication) and Hawaii (J.W. Armstrong, Quarantine Scientific, personal communication) indicate that EF was not sufficiently effective to control internal fruit fly larvae to a standard acceptable to phytosanitary authorities. However, the EF rates and exposure times tested for those

experiments were not immediately available. In this study, codling moth infested apples exposed to a mean of $2.43 \%$ EF resulted in $85.2 \%$ mortality of the CM larvae inside apples. This level of control while unsuitable as a standalone treatment may prove useful as a component of a systems approach to manage codling moth where infestation rates are already extremely low.

This study did not examine the impact of EF 


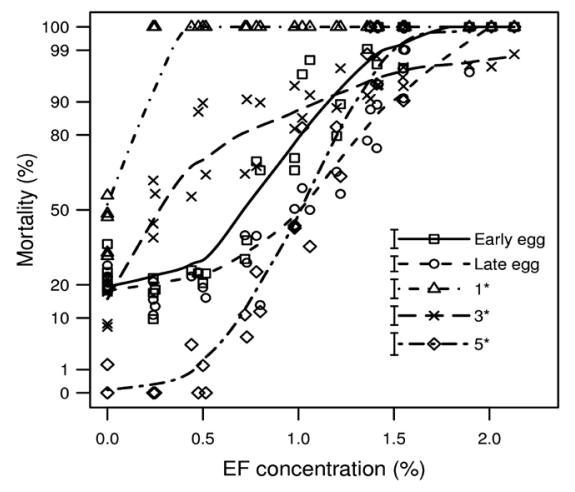

Figure 2 Mortality responses of codling moth early eggs, late eggs, $1^{\text {st }}$ instar larvae $\left(1^{*}\right), 3^{\text {rd }}$ instar larvae $\left(3^{\star}\right), 5^{\text {th }}$ instar larvae $\left(5^{\star}\right)$ exposed to a range of ethyl formate $(\mathrm{EF})$ concentrations (with $\mathrm{CO}_{2}$ ) $2 \mathrm{~h}$ at $15^{\circ} \mathrm{C}$. Mean measured $\mathrm{EF}$ concentrations are presented rather than target EF concentrations. Error bars represent approximately uniform variability over the entire mortality range on the arcsine scale.

on fruit quality. Previous research showed that EF can cause browning around the calyx of apples, but cold storage before EF significantly reduced the incidence and severity of calyx browning (LE Jamieson, Plant \& Food, unpublished). Preliminary fruit quality trials suggested that $2.43 \% \mathrm{EF}$ for $2 \mathrm{~h}$ may cause significant calyx browning in susceptible cultivars such as 'Scired'/Pacific Queen ${ }^{\text {TM }}$ and 'Scilate'/Envy ${ }^{\circledR}$. However, that concentration of EF may be tolerated by EF-tolerant cultivars such as 'Fuji', 'Scifresh'/Jazz ${ }^{\mathrm{TM}}$ and 'Braeburn' and stored 'Royal Gala' (for 4-8 weeks) (LE Jamieson, Plant \& Food, unpublished data).

Cycles of increasing and decreasing pressure from standard atmospheric pressure (ca 101 $\mathrm{kPa}$ range), have the potential to enhance insect mortality (Calderon \& Navarro 1968; Mbata et al. 2004). Metabolic-stress Disinfestation and Disinfection (MSDD) was developed to control of arthropods and pathogens (Lagunas-Solar \& Essert 2011; Lagunas-Solar et al.2006). Cycles of expansion and compression (physical phase), in combination with low vapour concentrations of ethanol applied with vacuum (chemical phase), were used to kill

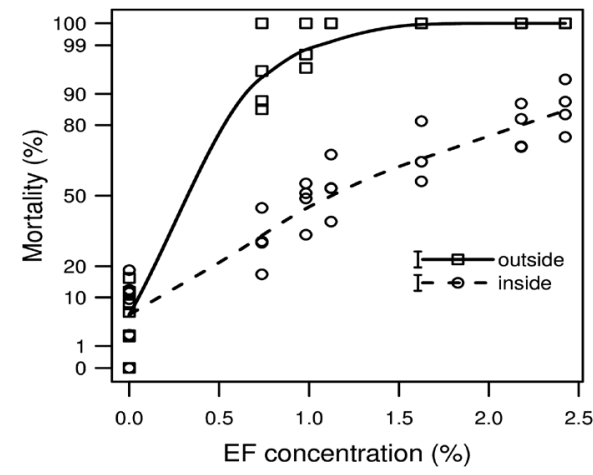

Figure 3 Mortality response of $4^{\text {th }} / 5^{\text {th }}$ instar codling moth larvae placed with apples either inside or outside fruit and exposed to various concentrations of ethyl formate (EF) for $2 \mathrm{~h}$ at $15^{\circ} \mathrm{C}$. Mean measured EF concentrations are presented rather than target EF concentrations. Error bars represent approximately uniform variability over the entire mortality range on the arcsine scale.

arthropods and pathogens. Similar research in New Zealand showed that both the physical and chemical (ethanol) phases were required to ensure high mortality of pests (Zulhendri 2012; Zulhendri et al. 2012a; Zulhendri et al. 2012b).

EF in combination with a vacuum or a modified MSDD process may increase the mortality of CM larvae located inside apples. A preliminary study that examined the effect of $2 \mathrm{~h}$ treatments applied to $\mathrm{CM}$ inside apples using a small vacuum $(90 \mathrm{kPa})$ with $\mathrm{EF}+\mathrm{CO}_{2}$, or cycles of expansion and compression between 90 and $110 \mathrm{kPa}$ followed by $\mathrm{EF}+\mathrm{CO}_{2}$ applied at a $90 \mathrm{kPa}$ pressure, were found not to enhance mortality (Jamieson et al. unpublished data). The next step for this research is to apply a larger vacuum (similar in size to that used in the MSDD system), which may cause > 99\% mortality of the most resistant stage of CM larvae inside at EF concentrations undamaging to apples.

\section{ACKNOWLEDGEMENTS}

The authors thank Bruce Freeth for his hard work in building and maintaining the VTF at 
PFR Auckland. Thanks also to Mr Apple, and the Hawkes Bay PFR team for supplying apples; to Anne Barrington and the Insect Rearing PFR team for supplying codling moth; Dominic Hartnett for excellent technical assistance; Miriam Hall, Matt Punter, Allan Woolf and Jason Johnston for conducting fruit quality trials referred to in the discussion; Dave Rogers and Allan Woolf for comments on the draft manuscript. This research was funded by Pipfruit New Zealand, MBIE Partnership Fund and PFR Core funding.

\section{REFERENCES}

Anon 1993. Notification No. 582. Modification of details concerning fixing the standard by the Minister of Agriculture, Forestry and Fisheries in connection with fresh apple varieties such as Gala, Granny Smith, Fuji, Braeburn, Red Delicious and Royal Gala shipped from New Zealand. Annex: 1(4). MAFF Japan Plant Quarantine Law.

Calderon M, Navarro S 1968. Sensitivity of three stored product insect species exposed to different low pressures. Nature 218: 190.

Chhagan A, Jamieson LE, Griffin MJ, PageWeir NEM, Poulton J, Zulhendri F, Feng R, Connolly PG, Davis VA, Olsson S, Redpath SP, Kean AM, Woolf AB 2013. Postharvest management of New Zealand flower thrips (Thrips obscuratus) on apricots using ethyl formate or pyrethrum-based treatments. New Zealand Plant Protection. 66: 63-74.

Cleveland WS, Grosse E, Shyu WM 1992. Local regression models. In: Chambers JM, Hastie TJ eds. Statistical Models in S. http://netlib. att.com/netlib/a/cloess.ps.Z, Wadsworth \& Brooks/Cole, CA. Pp. 309-376.

De Lima CPF 2009. Fumigation of table grapes using ethyl formate + carbon dioxide as a quarantine treatment Department of Agriculture and Food Western Australia.

De Lima CPF 2010. Fumigation of citrus using ethyl formate + carbon dioxide as a quarantine treatment Department of Agriculture and Food.
Dentener PR, Alexander SM, Petry RJ, O’Connor G, Lester P, Bennett KM, Maindonald JH 1998. Effect of combined methyl bromide fumigation and cold treatment on Cydia pomonella (Lepidoptera: Tortricidae) mortality on apples. Journal of Economic Entomology 91: 528-533.

Dobson AJ, Barnett AG 2008. Texts in Statistical Science: An Introduction to Generalized Linear Models. 3 ed. Florida, USA, CRC Press, Taylor \& Francis Group.

Drake SR, Moffitt HR 1998. Response of several apple cultivars to methyl bromide fumigation. HortTechnology 8(1): 64-68.

Ducom PJF 2006. The return of fumigants. In: Lorini I, Bacaltchuk B, Beckel H, Deckers D, Sundfeld E, dos Santos JP, Biagi JD, Celaro JC, Faroni LRDA, Bortolini LdOF and others eds. 9th International Working Conference on Stored Product Production, 15-18 October. Pp. 510-516.

EPA 2011. Methyl bromide fumigations: Postreassessment guidance for fumigators. Wellington, New Zealand, Environmental Protection Authority.

Griffin MJ, Jamieson LE, Chhagan A, PageWeir NEM, Poulton J, Davis VA, Zulhendri F, Connolly PG 2013. The potential of ethyl formate + carbon dioxide to control a range of horticultural pests. New Zealand Plant Protection 66: 54-62.

Jamieson LE, Griffin M, Page-Weir NEM, Chhagan A, Redpath S, Connolly PG 2014. Developing ethyl formate treatment for disinfesting pipfruit. New Zealand Plant Protection 67: 96-102.

Jamieson LE, Griffin MJ, Page-Weir NEM, Redpath SP, Chhagan A, Connolly P, Woolf $\mathrm{AB}$ 2015. The tolerance of tomato potato psyllid life stages to ethyl formate. New Zealand Plant Protection 68: 91-97.

Jamieson LE, Page-Weir NEM, Chhagan A, Connolly PG, Poulton J, Kean AM 2013. The potential of using low oxygen and ethyl formate or ethyl acetate to disinfest fresh fruit in storage. NZ Plant Protection 66: 45-53

Lagunas-Solar M, Essert T 2011. Disinfestation 
and Disinfection of food, perishables and other commodities. USA, Patent.

Lagunas-Solar MC, Essert TK, U CP, Zeng NX, Truong TD 2006. Metabolic stress disinfection and disinfestation (MSDD): a new, non-thermal, residue-free process for fresh agricultural products. J. of the Science of Food and Agriculture 86(12): 1814-1825.

Mbata GN, Phillips TW, Payton M 2004. Mortality of eggs of stored-product insects held under vacuum: Effects of pressure, temperature, and exposure time. Journal of Economic Entomology 97(2): 695-702.

Ministry for Primary Industries 2013. MPI Phytosanitary Official Assurance Programme for the Export of Apples to Taiwan 20132014. Ministry for Primary Industries. http:// www.biosecurity.govt.nz/files/regs/exports/ plants/apples/apples-taiwan-complianceprogramme.pdf [accessed 15 Feb 2014].

Preisler HK, Robertson JL 1989. Analysis of timedose-mortality data. Journal of Economic Entomology 82: 1534-1542.

Pupin F, Bikoba V, Biasi W, Pedroso G, Ouyang Y, Grafton-Cardwell E, Mitcham E 2013. Postharvest control of western flower thrips (Thysanoptera: Thripidae) and California red scale (Hemiptera: Diaspididae) with ethyl formate and its impact on citrus fruit quality. Journal of Econmoic Entomology 106(6): 2341-2348.

$\mathrm{R}$ Core Team 2015. R: A language and environment for statistical computing. Vienna, Austria., R Foundation for Statistical Computing, .

Rogers D, Bycroft B, Somerfield K, Brash D, Klementz D, Cole L, Sharma N, Taylor N, Page B, Connolly P 2013. Efficacy of phosphine fumigation of apples for codling moth (Cydia pomonella) disinfestation. New Zealand Plant Protection 66: 75-81.

Schimanski LJ, Jennings D, Brown G 2005. Overcoming fumigation damage of 'Fuji' apples destined for Japan. Acta Horticulturae (682): 1185-1191.

Simpson T, Bikoba V, Mitcham EJ 2004. Effects of ethyl formate on fruit quality and target pest mortality for harvested strawberries. Postharvest Biol. \& Tech. 34(3): 313-319.

Simpson T, Bikoba V, Tipping C, Mitcham E 2007. Ethyl formate as a postharvest fumigant for selected pests of table grapes. Journal of Econmoic Entomology 100(4): 1084-1090.

Soma Y, Ikeda T, Kawakami F 1997. Phytotoxic responses of several apple varieties to methyl bromide, phosphine and methyl isothiocyanate fumigation. Research Bulletin Plant Protection Japan 33: 61-64.

UNEP 2012. Handbook for the Montreal Protocol on Substances that Deplete the Ozone Layer. Ninth Edition. Control measures. Article $2 \mathrm{H}$ paragraph 6. http://ozone.unep.org/en/ handbook-montreal-protocol-substancesdeplete-ozone-layer/16.

van Epenhuijsen CW, Hedderley DI, Somerfield KG, Brash DW 2007. Efficacy of ethyl formate and ethyl acetate for the control of onion thrips (Thips tabaci). Journal of Crop and Horticultural Science 35: 267-274.

Waddell B 1993. Japanese market access for New Zealand apples: development of a postharvest disinfestation treatment for codling moth. New Zealand Institute of Agricultural Science and the New Zealand Society for Horticultural Science. Annual Convention, August 1993. Weston GC ed. Pp. 31.

Zulhendri F 2012. Investigation of MetabolicStress Disinfection and Disinfestation (MSDD) as An Alternative to Methyl Bromide for Disinfestation. Auckland University.

Zulhendri F, De Sliva HN, Jamieson LE, Perera CO, Quek SY, Woolf A 2012a. Otimizing metabolic stress disinfection and disinfestation components to control Pseudococcus longispinus. Journal of Economic Entomology 105(4): 1171-1177.

Zulhendri F, Jamieson L, Perera C, McDonald R, Connolly P, Quek S, Woolf A 2012b. The effect of metabolic stress disinfection and disinfestation (MSDD) on 'Hass' avocado fruit physiology and mortality of longtailed mealybug (Pseudococcus longispinus). Postharvest Biology and Technology 64: 138145. 